neither can be compare the UK in 1946, when there were 3 million motors, and in 1974, when there were 17 million. We must have some comparative rate, and if this is improving we are entitled to claim that we are making progress. The large number of deaths is at least partly due to the enormous number of motors. It is also remarkable that your profession, who are in the best position to know, should neglect the large saving in lives made by the motor in enabling you to get to your patients more quickly and to get them to hospital promptly, in enabling the fire brigade to reach fires early, and so on.

This mistake has been made twice, if not three times, with tragic results, Between 1946 and 1956 the number of deaths rose slightly, although the "Smeed rate"- which allows for the population and number of motors-and the deaths per 100 million vehicle-kilometres both fell markedly. The rise in deaths, slight though it was, was blamed wholly on the drivers, though the number of motors had risen from 3 million to $6 \frac{1}{2}$ million. An Act increasing penalties was passed, the trend of the deaths rose sharply, and both rates rose. This was again blamed on the drivers and another Act, much increasing penalties, was passed in 1962. The deaths then rocketed upwards to the highest they have ever been, almost 8000 , the rise being as much as 1100 in one year. When they fell again in 1967 the fall was claimed for the alcohol regulations in spite of many other measures taken at the same time which would reduce the deaths. The rises were ignored. The deaths then rose again and nearly reached the "Marples" summit. The probability is that all three Acts increased the deaths.

I agree with you about the recording of accidents and strongly condemn the popular use-once again even by the RRL-of the word "casualty" for minor bruises and cuts. Worse still is the use of the word "maim" for these, though I think I heard-at 77 my hearing is not $100^{\circ}{ }_{0}-\mathrm{a}$ prominent member of your Association do it on TV recently.

Unfortunately, however, it does not seem possible to get the full information about the human factors. I have tried it. You must remember that the object of accident investigation at present is to find out if a driver-and a driver only-can be prosecuted, and once that has been decided the armour-plated door clangs to and nothing more can be done. I even tried to find out whether drivers concerned were local and knew the road-important information-in my studies. The chief constable refused to ask this question on the grounds that it might produce prejudice. I could not argue with him. God knows there is enough prejudice already. I think you will find that to get the information needed would need the total reform of the law, though this is badly overdue. You must, however, remember that we engineers know how to stop the accidents. We have done it many times. I have done it. What we need is the money.

J J LEEMING

Buckfast, Devon Former County Surveyor of Dorset

\section{Clinical integration}

SIR,-Your leading article (23 October, p 964) does not mention the vast financial saving to the NHS which would result from co-ordination of hospital and general practitioner services. The present arrangement of large outpatient follow-up clinics in hospital duplicates much of the GP's work and is wasteful of scarce NHS resources. The four common disorders of dyspepsia, stroke, hypertension, and diabetes which you mention are far better cared for in general practice; I do not think that reliable readings of blood pressure and blood sugar can be obtained in the hospital outpatient clinic. However, the problem of long-term follow-up and chasing up of defaulters is one which has not yet been solved in general practice and is an area which could well benefit from hospital experience.

Integration should also involve the social services. A great deal of the work in general practice would be done better by a social worker attached to the practice as a member of the primary health care team. Pooling of information and resources would again make an enormous financial saving.

George STRUbe

Crawley, Sussex

\section{Survival at sea}

SIR,-May I draw attention to an error in your leading article on this subject (30 October, p 1026)? The first step in improving naval lifesaving equipment after the second world war was the inflatable lifejacket, not the liferaft. ${ }^{1}$

May I also comment on the statement that the survivor's need is for water rather than food, except in extreme cold? Lest it be inferred that water is not important in cold climates it should be noted that many seafarers in antarctic seas have reported to the contrary -for example, Sir Ernest Shackleton, "Thirst took possession of us. . . . Lack of water is always the most severe privation that men can be condemned to endure,"' Commander F A Worsley, RN, "All hands were suffering from the sensation of thirst. ... Our raging thirst prevented us from eating,", 3 and more latterly Dr David Lewis, "Chronic thirst remained a constant preoccupation. Two fingernails came off today." 4 Wartime survivors in arctic seas likewise reported their craving need for water; one stated, "No one ate very much, nor complained of being hungry, but we all craved for a drink.",

Bath

E C B LEE

Holt, W J, Transactions of the Institution of Naval Architects, 1955, 95, 332

Shackleton, E H, South. London, Heinemann, 1919. Worsley, F A, Shackleton's B

Lewis, D Ice Bird. London, Collins, 1975.

Lee, E C B, and Lee, K, Exposure at Sea. Proceed ings, Studies Section, International Radio Medical Centre, Rome 1968.

\section{Diets for diabetics: no added sucrose}

SIR,-My recent letter (23 October, p 1011) contained a mistake about the sucrose content of Professor J W Anderson's diabetes diet. The sugars in the US diet average $20-25 \%$ energy and in the diet of the American Diabetes Association are about $20 \%$. Dr Anderson had reported that the proportion of "oligosaccharides"-that is, sugars-in his diet was $20 \%{ }^{1}$ A colleague pointed out that I should not regard these as sucrose, but by then it was too late to prevent publication of my letter. I wrote to Dr Anderson in Kentucky for more details of his diet, previously not published. He replied very kindly and promptly (27 October) that "our diets contain about $25 \%$ of total carbohydrate as simple sugar." (From previous letters and articles I had misinterpreted this to signify "simply sucrose"). But the letter continued "no added sucrose . . . less than $20 \mathrm{~g}$ per day". I also noted that fat had with safety been increased from $9 \%$ to $15 \%$, thus increasing palatability. There are each day 13 servings of wholemeal bread and five servings of starchy vegetables. After two weeks' hospital treatment over 20 diabetics have been able to discontinue sulphonylurea; also those receiving 15-25 $\mathrm{U}$ of insulin each day have been able to discontinue it, but not those requiring more.

Hugh Trowell

Woodgreen,

Fordingbridge, Hants

${ }^{1}$ Kiehm, T G, Anderson, J W, and Ward, K, American fournal of Clinical Nutrition, 1976, 29, 895.

\section{Hypotension during angiotensin blockade} with saralasin

SIR,-Sodium depletion has been commonly recommended to identify angiotensinogenic hypertension with the competitive angiotensin antagonist saralasin. ${ }^{1}$ However, the decrease of blood pressure obtained after saralasin infusion in a severely sodium-depleted state may give more information about the extent to which the renin-angiotensin system was stimulated than about the true angiotensindependent nature of the hypertension itself. Moreover, saralasin infusion in a severely sodium-depleted subject may lead to a dangerous fall of blood pressure, as was demonstrated by $\operatorname{Dr} R$ Beckerhoff and his colleagues (9 October, p 849). In addition to their findings we would like to report our experience with saralasin infusions in a hypertensive patient before and after six days' treatment with chlorthalidone $100 \mathrm{mg}$ daily.

The patient was a 43-year-old man with a blood pressure of $175 / 120 \mathrm{~mm} \mathrm{Hg}$. Renal arteriography showed a severe proximal stenosis of the left renal artery. The patient received no medication. After three hours of recumbency saralasin was infused at increasing rates $(0.5,5$, and $10 \mathrm{ng} / \mathrm{kg} / \mathrm{min})$ while the patient was on moderate sodium intake (urinary sodium excretion $93 \mathrm{mmol}(\mathrm{mEq} / 24 \mathrm{~h}$ ). Blood pressures were recorded automatically by an Arteriosonde. Only a small decrease of blood pressure, from $160 / 110$ to $150 / 108 \mathrm{~mm} \mathrm{Hg}$, was recorded after $45 \mathrm{~min}$ of saralasin infusion (see figure). A short initial rise of blood pressure was noted within $5 \mathrm{~min}$ after the beginning of the lowest infusion rate. After six days chlorthalidone $100 \mathrm{mg} / \mathrm{d}$, resulting in a $2.8 \mathrm{~kg}$ decrease of body weight, an immediate fall in blood pressure from $136 / 108$ to $108 / 87 \mathrm{~mm} \mathrm{Hg}$ was observed at the

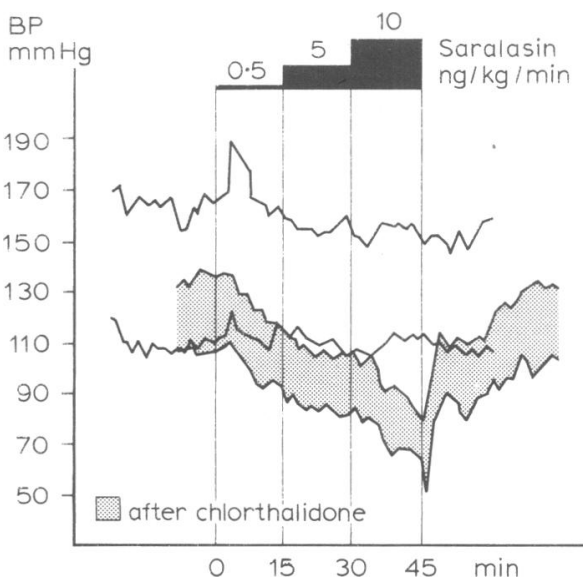

Blood pressure recording during saralasin infusion before and after sodium depletion with chlorthalidone $100 \mathrm{mg}$ daily for six days. 
lowest saralasin infusion rate. At the higher infusion rates blood pressure decreased continuously to a minimum of $75 / 55 \mathrm{~mm} \mathrm{Hg}$ at the end of the infusion period. At that moment the patient fel seriously ill, had a pale complexion, and vomited several times. After the infusion was stopped the blood pressure reached its preinfusion level within $30 \mathrm{~min}$. Plasma renin activity (PRA) was measured at the beginning and the end of each infusion (see table).

\begin{tabular}{c|c|c} 
& PRA $(\mu \mathrm{g} / 13 \mathrm{~h})$ \\
\hline $\begin{array}{c}\text { Moderate sodium intake } \ldots \\
\text { After six days chlorthalidone } \\
100 \text { mg day }\end{array}$ & $\begin{array}{c}\text { Before } \\
\text { saralasin }\end{array}$ & $\begin{array}{c}\text { After } \\
\text { saralasin }\end{array}$ \\
\hline
\end{tabular}

The findings in this patient show firstly that saralasin infusion may lead to a potentially hazardous initial rise in blood pressure when PRA is low, as has been demonstrated by others, ${ }^{2}$ and secondly that saralasin infused after severe sodium depletion with chlorthiazide diuretics and vigorously stimulated PRA may cause severe hypotension even at low-dose infusion rates.

W H L HoEFNagels TH THIEN

Department of Internal Medicine,

St Radboud Hospital,

University of Nijmegen,

Streeten, D H P, et al, Circulation Research, 1975, 36, suppl I, p 125 .

${ }^{2}$ Case, D B, et al, American fournal of Medicine, 1976 , 60, 825.

\section{There's slow release and slow release}

SIR,-In recent years several papers and letters have appeared in your columns ${ }^{1-3}$ warning against the hazards of sustained-release oral preparations, the latest being that of $\mathrm{Dr} I \mathrm{P}$ Carne-Ross (11 September, p 642). We are dismayed to see that the importance of the pharmaceutical formulation of such products is never stressed, and we feel that the time has come to draw attention to the matter.

To achieve controlled release, including slow release, of an orally administered drug at least two essentially different principles may be employed: the one-unit dose (for example, matrix tablets) and the multiple-units dose (for example, pellets or individually coated crystals distributed in capsules or tablets). The most importance distinction between these two principles lies in the fact that while a matrix tablet travels through the entire gastrointestinal tract remaining one nondisintegrated unit, the pellets or coated crystals are dispersed from the moment the capsule or tablet disintegrates, and $x$-ray studies $^{45}$ indicate that the spreading throughout the gastrointestinal tract is a function of time only.

Apart from carrying an almost negligible risk of the drug depot being trapped and causing local irritation and/or ulceration, the multiple-units dose possesses further advantages: the optimal absorption sites-generally localised in the small intestine-are reached earlier and better utilised because the emptying rate of the stomach is not a limiting factor for the onset of absorption from the small intestine, as in general is the case with a large compact unit, the effect of which must await its passage through the pylorus. Thus the importance of individual variations in stomach empyting rate and transit time as a whole is diminished and the predictability of the effect of a given dose is therefore increased.

In conclusion, we submit that when a controlled-release preparation of a drug is needed more care should be taken to secure that the formulation prescribed is in fact appropriate.

HELLE BECHGAARD GYDA H NIELSEN

A/S Alfred Benzon, Copenhagen,

Spigelman, M, and McNabb, R W, British Medical fournal, 1971, 2,534.

2 Alaily, A B, British Medical fournal, 1974, 1, 103. Howie, A D, and Strachan, R W, British Medical fournal, 1975, 2, 176

Green, M A, Annals of Allergy, 1954, 12, 273. Feinblatt, T M, and Ferguson, E A, New England
fournal of Medicine, 1956, 254, 940 .

\section{Prematurity and neonatal death}

SIR,-Mr R M Rush and his colleagues (23 October, $p$ 965) have pointed out the relationship between preterm delivery and neonatal mortality. This is certainly in keeping with our experience. They state that prediction of preterm delivery is very difficult. Unfortunately, they have not reviewed previous obstetric history in their study.

During 197515 neonates died in this hospital, largely as a consequence of preterm delivery. Five of their mothers admitted to previous terminations; three were unmarried at the time of delivery; two were under the age of 16 and one over 40 ; two had had previous spontaneous abortions; three had a previous history of infant death; three were para 5 or more; one had had no antenatal care; two had had previous serious subfertility; two were delivered before arrival; two had had previous low-birth-weight preterm infants; one had had a previous infant with severe rhesus disease.

Only two of the 15 mothers had no adverse obstetric factors and were married girls in their early 20 s. In contrast, preterm deliveries without these adverse factors (the vast majority) seem to have a good outcome in our experience.

Legal termination is followed by greatly increased fetal loss ${ }^{1}$ from all causes, including neonatal death and preterm delivery, especially when cervical laceration has occurred.

\section{JANET HUNTER}

JOHN DAVIES

Grimsby Maternity Hospital,

Grimsby,

S Humberside

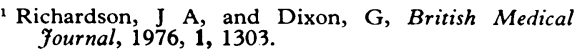

\section{Palindromic rheumatism}

SIR,-The short report by Dr E C Huskisson (23 October, p 979) is important for two main reasons. The first is that although palindromic rheumatism is a loose, ill-defined entity, in Britain it would appear to be often due to rheumatoid arthritis in episodic recurrent form, sometimes subsiding spontaneously, sometimes turning out to be a manifestation of some other disorder such as a reticulosis, but not infrequently gradually evolving into the clinical pattern of classical rheumatoid arthritis. In the past 30 years I have seen six such patients who in time became manifestly cases of rheumatoid arthritis, one remarkable in that for 20 years he suffered typical intermittent attacks of arthritis, with episodes of pain, stiffness, and swelling occurring for two or three days every few weeks or months and resolving completely each time until finally he was admitted to hospital with classical seropositive rheumatoid arthritis. What the original condition was that was described under the title of "palindromic rheumatism" by Hench and Rosenberg ${ }^{1}$ is uncertain. Their cases were observed in military personnel in the USA during the last world war and do not seem to be the same disorders that we see in Britain today. Whatever palindromic rheumatism is will vary with the country from which it is described and the different infective and rheumatic processes prevalent at the time in that area. But the treatment of the different non-infective inflammatory arthropathies does not differ very greatly. In the absence of a known aetiology treatment is essentially symptomatic and palliative.

The second reason for emphasising the importance of palindromic rheumatism is that here we have an inflammatory polyarthritic process spontaneously switching on and off. Whatever factors or therapeutic agents will influence this disorder may well give us a lead to future therapeutic advances. In the past 30 years we have not infrequently seen the development of effective new drugs alter our ideas as to aetiology and pathological mechanisms in the arthritic disorders. Given a form of therapy which manifestly has positive action there will be no shortage of theories to explain that therapeutic effect. In medical therapeutics the cart has pulled the horse as often as not. So this small series of cases of a rare disorder and the effect on them of $D$ penicillamine described by Dr Huskisson is of particular interest and of some importance.

\section{F DUdLEY HART}

London W1

'Hench, P S, and Rosenberg, E F, Archives of Internal Medicine, 1944, 73, 293.

\section{Comparative diagnostic accuracy of barium meal and endoscopy}

SIR,-In commenting on the study by Dr G W Stevenson and others (25 September, p 723), Dr M W Dronfield and his colleagues make some remarkable statements (23 October, p 1010). Surely a department of radiologists is entitled to be interested in diagnostic accuracy? The quality of their study adds considerable weight to the results of many others (including Dr Dronfield's) and to the increasing clinical consensus that endoscopy has greater potential than radiology in acute bleeding. In many hospitals the urgent barium meal has virtually been forgotten. Many comparative studies have been stopped, like that of Dr Stevenson and his colleagues, when 'the physicians' preference for endoscopic demonstration of the bleeding site became too strong for random allocation to continue." Have not Dr Dronfield and his colleagues encountered similar problems in their randomised study? Are Nottingham physicians and surgeons really prepared to treat patients on the basis of an equivocal or negative barium meal when presumably expert endoscopy is available?

Dr Dronfield's letter suggests that $\mathrm{Dr}$ Stevenson's study was irrelevant. While I agree that the diagnostic argument can reasonably be closed, I believe that $\mathrm{Dr}$ Dronfield and his colleagues are also doing 